\title{
Exploratory Study of the Effect of Obstetric Psychoprophylaxis on the Cortisol Level in Pregnant Women, Huancavelica - Perú
}

\author{
Lina Cardenás-Pineda ${ }^{1}$, Alicia Alva Mantari ${ }^{2}$, Rossibel Muñoz ${ }^{3}$ \\ Gabriela Ordoñez-Ccora ${ }^{4}$,Tula Guerra ${ }^{5}$, Sandra Jurado-Condori ${ }^{6}$ \\ Universidad Nacional de Huancavelica ${ }^{1,3,4,5,6}$ \\ Image Processing Research Laboratory (INTI-Lab) \\ Universidad de Ciencias y Humanidades ${ }^{2}$
}

\begin{abstract}
Objective: To determine the cortisol level of patients who make use of the Obstetric Psychoprophylaxis (OPP) service in a first-level health center, February - May 2018. Material and methods: Descriptive, prospective, cross-sectional. Results: $68.75 \%$ of pregnant women have a stable conjugal relationship, while $\mathbf{2 5 \%}$ are single and $\mathbf{6 . 2 5 \%}$ separated, $\mathbf{5 0 \%}$ have a higher education degree and $50 \%$ have a secondary education degree. Apparently, cortisol does not change according to gestational age, however, the number of OPP sessions influences the level of cortisol, so more assisted sessions means less cortisol. Conclusion: the greater exposure to obstetric psychoprophylaxis, the less levels of cortisol am (morning) in serum are observed. It could be due to psychoprophylaxis has a component that works the mental state; further studies are recommended.
\end{abstract}

Keywords-Cortisol; obstetric; psychoprophylaxis; pregnant women; sessions; gestational; serum; observed

\section{INTRODUCTION}

Cortisol is a steroid hormone produced by the adrenal gland, which performs multiple beneficial functions in the body in adequate concentrations, however, chronic exposure to inappropriate concentrations (high or low) produces considerable changes in tissues and organs [1], [2].

The excessive production of this hormone will be closely related to endocrine pathologies and to the body's response to stressful stimuli that occurs at the behavioral, endocrine and autonomic nervous system levels [3], there is scientific evidence that indicates that cortisol is an indicator stress and has a close relationship with the diagnosis of psychological problems such as depression and anxiety.

However, high levels of this hormone can cause other disorders, such as suppressing the immune system, making it more likely in stressful situations to have other types of conditions, infectious and non-infectious [4] [1].

During pregnancy, a series of modifications happens, in which there is a close relationship between physiological and psychological changes [5] the pregnant woman is more sensitive to stressful stimuli, where character changes are notorious, since it is not only influenced by pregnancy, also other factors of their environment such as family violence, and the economic deprivation [6].
Situations of anxiety and depression can modify maternal neuroendocrine function producing high levels of cortisol during pregnancy, this is negatively correlated with the fetus since it can have an impact on fetal neurological development [7] therefore they recommend making a separate evaluation of subjective measures and biological aspects of stress.[8].

On the other hand, there is evidence that relaxation techniques such as yoga, massage and aromatherapy have decreased cortisol levels in pregnant women, since when this hormone is produced in excessive amounts, it can affect the brain, immune system and organs of the pregnant woman and the intrauterine baby [9], [10].

On the other hand, obstetric psychoprophylaxis is a maternal education service, which aims is to prepare the mother for the reproductive process, this technique involves preparing the mother in three aspects, in basic knowledge, the physical and emotional part, the team believes that this could have an impact on cortisol concentrations at the level of maternal circulation, other indications that support our empiricism are the benefits of obstetric psychoprophylaxis that Molina M, Martínez A, Martínez F. propose for the physical and mental state of mother and newborn [11]. Likewise, Martínez found, regarding the benefits of obstetric psychoprophylaxis in the newborn, that is decrease low birth weight and better state at birth [12] [13]. For this reason, the importance and need to evaluate the cortisol level in pregnant women who attend obstetric psychoprophylaxis sessions.

This research was carried out with the aim of seeking techniques or strategies to decrease the level of cortisol in the pregnant mother, since this hormone in high amounts has been shown to be harmful because it has negative effects such as: inhibiting osteoblastic function, decreasing the immune response, increase blood pressure, sodium retention and potassium loss, decrease in Thyroid-Stimulating Hormone (TSH) synthesis and release, cataract, and effects on the nervous system (irritability, depression, memory disorders and concentration), all in the mother. However, it also affects the fetus, since this hormone stimulates apoptosis in some organs [14], produces low birth weight, cardiometabolic disorders, increased blood pressure, behavioral disorders, and altered brain structure [7]. 
This research serves as a basis for conducting other more exhaustive studies on the subject with the aim of finding alternatives that decrease the production of cortisol in pregnant women.

\section{STATE OF THE ART}

Chen, et al. [9] in her research "Effects of Aromatherapy Massage on Pregnant Women's Stress and Immune Function" published in 2017 in Taipéi City, a longitudinal, prospective, randomized study using Clinstat's blocked randomization; conformed by 52 pregnant women, whose intervention group were 24 and control group 28. It was found that they had lower salivary cortisol values $(\mathrm{p}<0.001)$ and higher Immunoglobulin A ( $p<0.001)$ than the intervention group, having as a conclusion that massage and aromatherapy reduces stress and improves immune function in pregnant women, therefore they recommend massage and aromatherapy for pregnant women.

Scharlau el at. [15] in her research "Evaluation of hair cortisol and cortisone change during pregnancy and the association with self-reported depression, somatization, and stress symptoms" conducted between December 2011 and November 2014, a longitudinal study made up of 62 pregnant women. It found that the cortisol level is higher in pregnant women of the third trimester compared to the second trimester.

\section{PREvious KnOWledGe}

\section{A. Cortisol}

It is a glucocorticoid produced by the adrenal gland, in adequate concentrations, they give various benefits on the organism such as preserving homeostasis, metabolism of carbohydrates, proteins and fats, and having a pertinent response to stress and inflammation [2], [5]. However, in high amounts, it can inhibit osteoblastic function, decrease the immune response, increase blood pressure, sodium retention and loss of potassium, decrease in TSH synthesis and release, cataract, and effects on the nervous system (irritability, depression, memory and concentration disorders), in the mother [1]. However, overexposure of the developing fetus to glucocorticoids produces low birth weight, cardiometabolic disorders, increased blood pressure, behavioral disorders, and altered brain structure [7].

Cortisol is increased in situations of anxiety and depression, very common during pregnancy due to the neuroendocrine modifications that occur [16]; this emotional disturbance of pregnancy can be identified subjectively using measurement tests and objectively or biologically by identifying the level of cortisol in blood, saliva, hair and urine [8], [17].

TABLE I. NoRmal VAlues OF CORTISOL IN SERUM

\begin{tabular}{|l|l|}
\hline Time & Value \\
\hline $8: 00$ Hours & $10 \mathrm{ug} / \mathrm{dl}-25 \mathrm{ug} / \mathrm{dl}$ \\
\hline $20: 00$ Hours & $7.5 \mathrm{ug} / \mathrm{dl}-18.75 \mathrm{ug} / \mathrm{dl}$ \\
\hline $00: 00$ Hours & $<7.5 \mathrm{ug} / \mathrm{dl}$ (awake) \\
\hline & $<1.8 \mathrm{ug} / \mathrm{dl}$ (asleep) \\
\hline
\end{tabular}

1) Cortisol biosynthesis: Steroidogenesis involves the concerted action of various enzymes, such as cytochrome P450; the limiting step in the synthesis of cortisol is the transport of free cytoplasmic cholesterol to the mitochondria, the place where the enzyme desmolase is located, it is the regulatory protein for steroidogenesis, subject to the influence of Adrenocorticotropic hormone (ACTH) and other factors nuclear.

After cholesterol enters the mitochondria, the side chain at position $\mathrm{C} 20$ is removed and forms pregnenolone; this happens in three steps regulated by the enzyme desmolase.

- The 3- $\beta$-HSD enzyme in the cytosol converts pregnenolone to progesterone, this enzyme is only appeared in the adrenals and gonads.

- 17a-hydroxylase, catalyzes the hydroxylation of progesterone and pregnenolone (activity in C17) and also removes the two-carbon side chain (17,20-lyase activity).

Substrates of 17a-hydroxylase activity, with the side chain intact, are glucocorticoid precursors, while the generation of C19 steroids, modified by 17a-hydroxylase and 17,20-lyase activity, produces sex steroids (androgens and estrogens). On the other hand, progesterone and $17 \mathrm{a}-\mathrm{OH}-$ progesterone are 21 hydroxylated by the enzyme 21-hydroxylase to form, respectively, 11-deoxycorticosterone and 11-deoxycortisol.

The final step in the synthesis of cortisol is the conversion of 11-deoxycortisol to cortisol by $11 \beta$-hydroxylase, a desmolase-like mitochondrial enzyme in its structure [1].

2) Glucocorticoid (cortisol) release: Glucocorticoids, synthesized by the adrenal cortex, are essential for life since they act on multiple tissues, triggering a variety of responses that play a very important role in adapting the body to a stress situation [18].

Cortisol release is under direct stimulation of ACTH released from the adenohypophysis that follows a circadian rhythm that is extremely sensitive to light, sleep, stress, and disease. Cortisol values are maximum at 08:00 h., they decrease passing the hours and are lower around 00:00 h, as the reader can see in Table I. [5], [17].

3) Cortisol mechanism of action: Steroids (cortisol and aldosterone) exert their metabolic effects after the uptake of the free hormone and its binding with intracellular receptors that are, respectively, the Glucocorticoid Receptor (GR) and the Mineralocorticoid Receptor (MR).

The gene for the glucocorticoid receptor is on chromosome 5 (q31-q32) and is expressed in most cells of the body, depending on the plasma cortisol concentration, the percentage of receptors bound to it will vary, between 10 and $70 \%$ under normal conditions. When GRs are not bound to cortisol, they complex with heat shock protein hsp90 (heat shock protein) and immunophilins, which makes their DNA affinity very low. 
These proteins are found in the cytosol regardless of the existence of GR receptors, and constitute an intracellular transport system for various proteins. Cortisol binds to its receptor in the same domain in which hsp90 proteins bind; therefore, the binding of cortisol to the receptor causes the receptor to dissociate from the hsp90 proteins and its subsequent translocation to the nucleus, once in the nucleus, the receptor-cortisol complex forms dimers that bind to DNA in regulatory or gene-promoting regions. Called GRE (elements that respond to glucocorticoids), or interact with other transcription factors linked to DNA, such as AP-1 or NFKB. GRs also exist in the cell membrane, the activation of which results in very rapid responses, for example, changes in the electrophysiological properties of neurons, magnitude and frequency of action potential, activity of calcium channels and release of hormones or neurotransmitters or some of the immunosuppressive actions on T cells.

Glucocorticoids, therefore, can act on their target cells in a number of ways: inducing transcription of a gene, such as those of Hepatic enzymes; inhibiting the transcription of a gene, such as the POMC in corticotropic cells; modulating the action of other transcription factors such as NFKB and, finally, acting through membrane receptors [1], [2].

4) Cortisol metabolism: The main place of degradation of cortisol is the liver, where through various processes, such as reduction, oxidation and hydroxylation of the molecule and its subsequent conjugation with glucuronic acid or sulfate, the production of water-soluble metabolites that are eliminated in the urine is achieved. Enzymes from the endoplasmic reticulum and the cytosol are involved in this process.

There are some diseases that cause alterations in cortisol metabolism; in hyperthyroidism, cortisol clearance increases, but since there is an increase in secretion, normal serum concentrations are maintained; while in hypothyroidism the cortisol clearance is decreased, as well as its secretion by the adrenals. This balance is achieved because the CRH-ACTHcortisol axis works properly and allows adjustments in ACTH secretion [1].

5) Cortisol effects: Effects on bone, muscle and connective tissue: In physiological concentrations, cortisol induces differentiation towards mature osteoblasts. If hypercortisolism exists, the following disorders occur:

- Inhibition of osteoblastic function and reduction in bone formation.

- Increased apoptosis of osteoblasts.

- Inhibition of bone growth.

- Decreased expression of the vitamin D receptor.

- Increased renal calcium excretion [1].

a) Effects on the metabolism of carbohydrates, lipids and proteins: Cortisol increases hepatic glucose production in prolonged periods of hypercortisolism, produces changes in the distribution of fat in the body: it increases the volume of visceral adipose tissue, in addition to depositing fatty tissue in the dorsocervical region, supraclavicular regions, trunk, mediastinum and mesentery with decreased adipose and muscular tissue in the extremities [1], [5].

b) Effects on fetal development: The fetal adrenal gland produces little cortisol until late stages of gestation. Its main products are pregnenolone sulfate and Dehydroepiandrosterone (DHEAS), which are detected around the 25th week of gestation, DHEAS can act as a cortisol antagonist and, in this way, protect the embryo from the catabolic effects of this substance, in addition to the fact that it seems to stimulate apoptosis in some tissues. Studies state that excess cortisol is related to low birth weight, cardiometabolic disorders, increased blood pressure, behavioral disorders, and altered brain structure [1], [7].

c) Effects on leukocyte and immune functions: Glucocorticoids decrease the immune response such as:

- Cause acute decrease in lymphocytes and eosinophils; while neutrophils increase.

- Decreased immunoglobulin synthesis.

- Less migration of neutrophils to places of tissue injury.

d) Effects on the cardiovascular system: Glucocorticoids increase blood pressure.

e) Effects on kidney function: Cortisol causes sodium retention and potassium loss, it also increases glomerular filtration rate and increases sodium transport at the proximal tubular level.

f) Effects on the central nervous system: Excess glucocorticoids initially produce euphoria. However, prolonged exposure generates irritability, emotional instability, depression and disorders in memory and concentration and, rarely, manic behavior and psychosis.

g) Effects on other hormones: Excess cortisol causes a decrease in the synthesis and release of thyroid stimulating hormone (TSH), it also causes a decrease in the pulsation of the Gonadotropin-Releasing Hormone (GnRH), which causes a decrease in the secretion Luteinizing Hormone (LH) and Follicle Stimulating Hormone (FSH).

h) Ocular effects: Glucocorticoids, by inducing aqueous humor production and protein deposition in the interstitial matrix, increase intraocular pressure in patients with open angle glaucoma, in addition to promoting cataract formation [1].

6) Glucocorticoid excess: Glucocorticoid excess may result from an adrenal tumor, excessive stimulation of adrenal glucocorticoid synthesis by ACTH produced for a pituitary tumor, or by iatrogenic administration of excess synthetic glucocorticoids. The clinical manifestations of glucocorticoid excess are known as Cushing's syndrome, which can be divided into two categories depending on its causes.

Cushing syndrome independent of ACTH is usually caused by adrenal neoplasms that autonomously release cortisol despite ACTH suppression. 
Excessive treatment with exogenous glucocorticoids is also a form of Cushing syndrome independent of ACTH [5].

7) Glucocorticoid deficiency: Glucocorticoid deficiency may be a consequence of lack of stimulation by ACTH for the production of adrenal glucocorticoids, also known as Addison's disease, it can be caused by exogenous administration of synthetic glucocorticoid analogues that suppress $\mathrm{CRH}$ and $\mathrm{ACTH}$, most of ACTH deficiency cases involve deficiencies in other pituitary hormones [5].

\section{B. Obstetric Psychopophilaxis}

Obstetric psychoprophylaxis according to the technical guide is an educational process for the comprehensive preparation of pregnant women, which allows them to develop healthy habits and behaviors, as well as a positive attitude towards pregnancy, childbirth, the puerperium, and the newborn, making this process in a happy and healthy experience for the mother, her baby and her family environment [13]. Whose onset is from 20 weeks of pregnancy.

1) Maternal benefits of obstetric psychoprophylaxis: It is recognized for reducing anxiety in the mother, the mother responds better to uterine contractions by applying breathing techniques, resulting in a shorter duration of the dilation and expulsion phase, fewer drugs are used, fewer maternal complications have been observed in the childbirth, active partner involvement and less incidence of postpartum depression have reported faster recovery and better breastfeeding [13].

2) Neonatal benefits of obstetric psychoprophylaxis: Fetal distress, perinatal complications, prematurity, and better birth weight were seen in mothers who received psychoprophylactic preparation [13].

3) Doctrinal basis of obstetric psychoprophylaxis: English school. (Grantly Dick Read), establishes an order of importance among the four elements: Education, Breathing Relaxation - Gymnastics.

Russian school. (Platonov, Velvovsky, Nicolaiev), establishes that the pain of childbirth is a conditioned reflex and therefore can be unconditioned.

French school. (Fernand Lamaze), Its theoretical bases are the same as those of the Russian school.

Eclectic school. (Leboyer. Gavensky, et al.), The eclectic school chooses the best of each school or theory, pointing its attention towards the newborn [19]. One of its objectives is to improve mental health due to the effects on both the mother and the baby.

\section{4) Methods and techniques of obstetric psychoprophylaxis}

a) Relaxation techniques: These are different activities that make the pregnant woman to a state of rest, both physical and mental, in order to achieve relief from tension or discomfort and improve her ability to concentrate [19].

b) Breathing techniques: These are the different ways of performing lung oxygenation, which in turn improves cell oxygenation in the mother and baby, depending on the time and need of the pregnant woman or parturient, thereby achieving greater comfort and relaxing [19].

c) Prenatal bonding techniques: Actions or dynamics that seek to promote the affective bond in the pregnant woman / pregnant couple and couple with the baby [19].

d) Visualization: Procedure by which images constructed based on motivation and thoughts are created mentally, especially during relaxation, to achieve a more enjoyable, pleasant and comforting emotional state [19].

e) Methods that can be used in obstetric psychoprophylaxis: There are various methods that can lead pregnant women to have a healthy emotional state such as aromatherapy, sphere dynamics, chromotherapy, massage therapy, hydrotherapy, music therapy, tai-chi, yoga [20].

5) Sessions: The sessions have a duration of one hour. The design of the session considers as activities: reception, basic concepts to make known, obstetric gymnastics, relaxation, recommendations or tasks and each of these have the techniques or methods, materials and time to use.

\section{Methodology}

\section{A. Type of Research}

The type of research is descriptive, cross-sectional, seeking to identify cortisol behavior in OPP users, that is, it is to measure or collect information independently or jointly on the variable under study [21].

\section{B. Population, Sample and Sampling}

The population was made up of 31 pregnant women who made use of the OPP service of the San Cristóbal Health Center of Huancavelica during the study period. The sample consisted of 16 pregnant women who met the inclusion criteria: no pathologies: endocrine, Cushing syndrome, kidney pathologies, kidney malformations, agree to participate in the study.

\section{Data Collection Techniques and Instruments}

Pregnant women were interviewed and medical records were reviewed in order to record the data requested in the cortisol measurement record instrument and to verify the inclusion criteria.

\section{Data Collection Procedures}

The corresponding permissions were requested from the health center [22].

1) Each of the pregnant women was informed of the process for informed consent one week before the sample was collected.

2) The sample was collected from pregnant women who agreed to participate in the study between 7:00 am to 9:00 am with the premise that they had not consumed any food 12 hours before taking it.

3) The sample was stored at $-20{ }^{\circ} \mathrm{C}$ in the laboratory of the San Cristóbal Health Center of Huancavelica 2018.

4) The samples were transferred to a laboratory in the city of Lima, keeping the temperature below zero. 
5) It was processed by a medical technologist, by the electrochemical technique with the C 111 SERIE 11246 ROCHE HITACHI MARCA ALEMANA equipment.

\section{RESULTS}

Table II shows that $68.75 \%$ of pregnant women are married or cohabiting, while $25 \%$ are single and $6.25 \%$ are separated. On the other hand, $50 \%$ of pregnant women have a higher education degree and the other ones $50 \%$ secondary degree.

Fig. 1 shows that gestational age does not influence the cortisol level in pregnant women who used the obstetric psychoprophylaxis service at the San Cristóbal Health Center in February-May 2018.

In Fig. 2, it shows how the cortisol level is related to the number of psychoprophylaxis sessions received by the pregnant woman.

TABLE II. Marital STATUS AND EdUCATION GRAdE OF PREgNANT WOMEN WHO USE THE OBSTETRIC PSYCHOPROPHYLAXIS SERVICE AT THE SAN CRISTÓBAL HEALTH CENTER OF HUANCAVELICA 2018

\begin{tabular}{|l|l|l|}
\hline & Fi & Fi \% \\
\hline MARITAL STATUS & & \\
\hline Single & 4 & 25 \\
\hline Separated & 1 & 6.25 \\
\hline In a Relationship & 11 & 68.75 \\
\hline TOTAL & 16 & 100 \\
\hline EDUCATION GRADE & & \\
\hline Initial & 0 & 0 \\
\hline Primary & 0 & 0 \\
\hline Secondary & 8 & 50 \\
\hline University Superior & 8 & 50 \\
\hline TOTAL & 16 & 100 \\
\hline
\end{tabular}

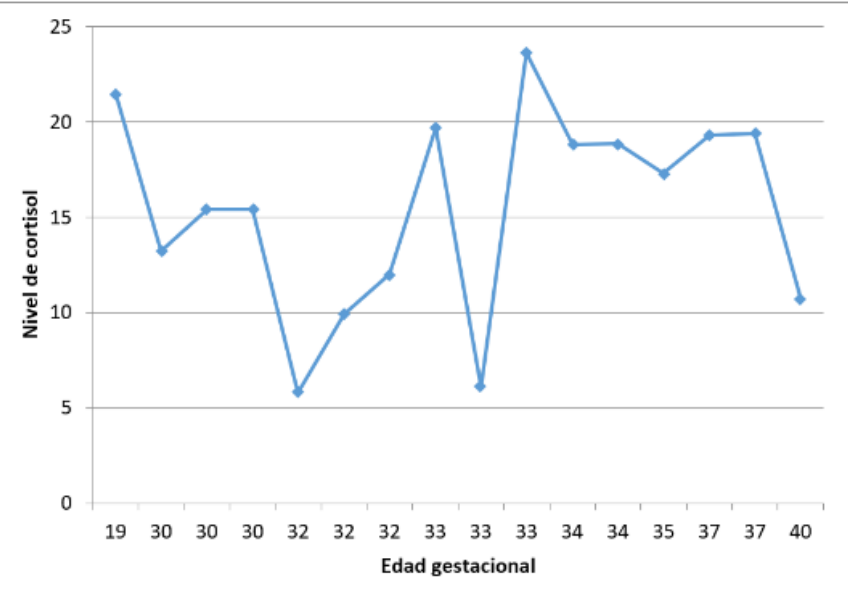

Fig. 1. Cortisol Level of Pregnant Women and Gestational Age at Sample Collection at the San Cristóbal Health Center February-May 2018.

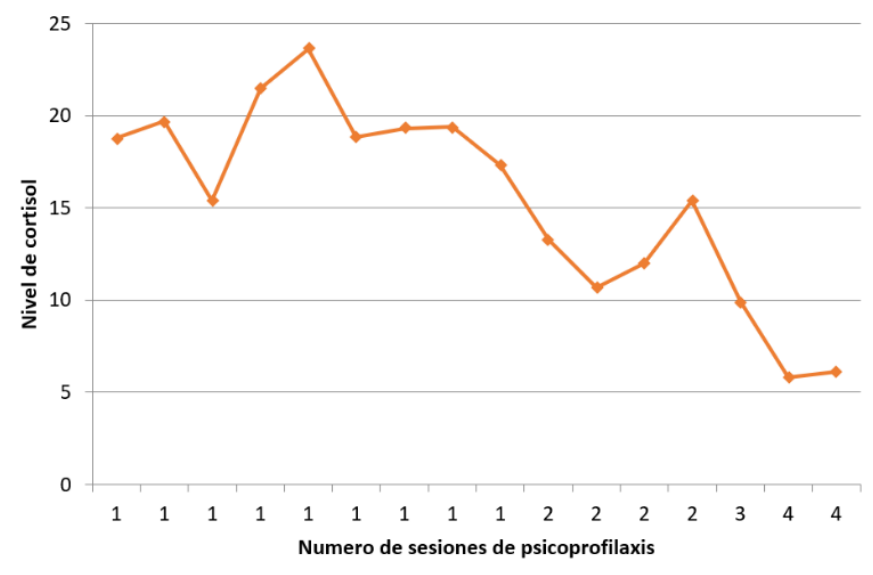

Fig. 2. Cortisol Level of Pregnant Women and Number of Obstetric Psychoprophylaxis Sessions at the San Cristóbal Health Center February-May 2018.

\section{DISCUSSION}

No variations in cortisol have been found due to gestational age, however, Scharlau finds that cortisol levels increase in the third trimester compared to the second trimester, this increase is probably because anxiety due to the proximity of the probable date of childbirth, which happens in pregnant women who have not received obstetric psychoprophylaxis or other methods of controlling anxiety and depression.

The cortisol levels of the pregnant women remained within the normal values, the minimum at 5.8 and the maximum at $23.6 \mathrm{ug} / \mathrm{dl}$ within the normal parameters reported by the laboratory $(3.95-27.23 \mathrm{ug} / \mathrm{dl})$. In this sense, it was identified that pregnant women who had more than two sessions of obstetric psychoprophylaxis have a decrease in AM cortisol level, the finding is due to obstetric psychoprophylaxis is a comprehensive program that prepares the pregnant woman to better face the stressful situations typical of the reproductive process. This result is supported by Chen [9] (2017) who finds lower salivary cortisol values in pregnant women who received aromatherapy and massage therapy in relation to those who did not. In the same way Chen [23], the same year found that prenatal yoga also decrease the level of salivary cortisol, and a year earlier Kusaka [10] had already identified that the mean concentration of salivary cortisol decreased after each yoga class. It should be noted that in this study, it was found that the level of cortisol will depend a lot on the number of sessions that the pregnant woman attends, being this a very beneficial for the mother and unborn child.

\section{CONCLUSIONS AND RECOMMENDATIONS}

The pregnant woman's cortisol level remained within the normal ranges $(5.8-23.6 \mathrm{ug} / \mathrm{dl})$, it was not affected by the gestational age, however, it is observed that as the number of PPO sessions increases, the Cortisol level tends to decrease, that is, the number of sessions influences the decrease in cortisol level in the study, showing the sensitivity of cortisol to obstetric psychoprophylaxis, the basis for subsequent research. 
Many studies about this topic are recommended to allow to analyze the effects of different relaxation techniques on the cortisol level and with serial measurements.

It is recommended that pregnant woman care programs incorporate obstetric psychoprophylaxis or maternal education as a transversal and compulsory axis.

\section{VIII.LIMITATIONS}

Among the limitations in this study, they are due to the reduced attendance at the obstetric psychoprophylaxis sessions, as part of a regular gestation process, mainly due to the culture of the rural Andean population. At the same time, the rejection of the pregnant woman to invasive processes, which limited to do only one control of cortisol and have as a sample of few participants.

\section{ACKNOWLEDGMENT}

We want to thank the Universidad Nacional de Huancavelica (UNH) for their support in this research.

To the San Cristobal Health Center for their valuable support in this research, and to recognize the heavy work that they do to develop the PPO sessions.

\section{REFERENCES}

[1] M. Cabrera Gámez, «Endocrinología y reproducción», Revista Cubana de Endocrinología, vol. 27, n.o 1, pp. 0-0, abr. 2016.

[2] Q. Araya Verónica, «Trastornos de la glándula suprarrenal: diagnóstico y tratamiento», Rev Med Clin Condes, vol. 24, n.o 5, pp. 768-777, sep. 2013, doi: 10.1016/S0716-8640(13)70222-0.

[3] G. G. D. L. Banda, M. ángeles Martínez-Abascal, M. Riesco, y G. Pérez, «La respuesta de cortisol ante un examen y su relación con otros acontecimientos estresantes y con algunas características de personalidad», Psicothema, vol. 16, n.o Número 2, pp. 294-298, dic. 2004.

[4] L. M. Dorantes-Álvarez y P. Medina-Bravo, «Ernest Starling y el nacimiento de la Endocrinología», Boletín médico del Hospital Infantil de México, vol. 62, n.o 5, pp. 307-309, oct. 2005.

[5] Elsevier, «"Tratado de Fisiología Médica": práctico, íntegro y bien estructurado», Elsevier Connect. https://www.elsevier.com/eses/connect/estudiantes-de-ciencias-de-la-salud/tratado-de-fisiologiaGuyton-Hall-11-edicion (accedido mar. 20, 2020).

[6] L. C. i Roura et al., Tratado de ginecología y obstetricia. 2014.

[7] R. M. Reynolds, «Glucocorticoid excess and the developmental origins of disease: two decades of testing the hypothesis--2012 Curt Richter Award Winner», Psychoneuroendocrinology, vol. 38, n.o 1, pp. 1-11, ene. 2013, doi: 10.1016/j.psyneuen.2012.08.012.

[8] M. J. Aguilar Cordero et al., «Cortisol salival como indicador de estrés fisiológico en niños y adultos: revisión sistemática», Nutrición Hospitalaria, vol. 29, n.o 5, pp. 960-968, may 2014, doi: 10.3305/nh.2014.29.5.7273.

[9] P.-J. Chen, C.-C. Chou, L. Yang, Y.-L. Tsai, Y.-C. Chang, y J.-J. Liaw, «Effects of Aromatherapy Massage on Pregnant Women's Stress and Immune Function: A Longitudinal, Prospective, Randomized Controlled Trial», J Altern Complement Med, vol. 23, n.o 10, pp. 778-786, oct. 2017, doi: 10.1089/acm.2016.0426.
[10] M. Kusaka, M. Matsuzaki, M. Shiraishi, y M. Haruna, «Immediate stress reduction effects of yoga during pregnancy: One group pre-post test», Women Birth, vol. 29, n.o 5, pp. e82-e88, oct. 2016, doi: 10.1016/j.wombi.2016.04.003.

[11] P. M. Escribano Alfaro, A. M. Martínez García, F. J. Martínez García, E. Gutiérrez Luque, R. Sáez Blázquez, y M. Molina Salmerón, «Impacto de la educación maternal: vivencia subjetiva materna y evolución del parto», sep. 1996, Accedido: mar. 20, 2020. [En línea]. Disponible en: https://ruidera.uclm.es/xmlui/handle/10578/308.

[12] J. M. M. Galiano, «Impacto del programa de educación maternal sobre la madre y el recién nacido», http://purl.org/dc/dcmitype/Text, Universidad de Granada, 2012.

[13] R. Hoyos y L. Marina, «Psicoprofilaxis obstétrica asociado a beneficios materno-perinatales en primigestas atendidas en el Instituto Especializado Materno Perinatal, enero-diciembre 2002», Universidad Nacional Mayor de San Marcos, 2004, Accedido: mar. 20, 2020. [En línea]. Disponible en: http://cybertesis.unmsm.edu.pe/handle /cybertesis/2985.

[14] C. Urosa, «Retos para el endocrinólogo en el siglo XXI», Revista Venezolana de Endocrinología y Metabolismo, vol. 7, n.o 1, pp. 1-2, feb. 2009.

[15] F. Scharlau et al., «Evaluation of hair cortisol and cortisone change during pregnancy and the association with self-reported depression, somatization, and stress symptoms», Stress, vol. 21, n.o 1, pp. 43-50, 2018, doi: 10.1080/10253890.2017.1392507.

[16] P. J. Brunton, «Effects of maternal exposure to social stress during pregnancy: consequences for mother and offspring», Reproduction, vol. 146, n.o 5, pp. R175-189, 2013, doi: 10.1530/REP-13-0258.

[17] J. M. Prieto Valtueña y A. Balcells Gorina, Balcells. La clínica y el laboratorio: interpretación de análisis y pruebas funcionales; exploración de los síndromes; cuadro biológico de las enfermedades. Barcelona; Masson: Elsevier ;, 2010.

[18] M. Hevia Suárez et al., «Manejo de la masa suprarrenal: lo que el urólogo debe saber», Actas Urológicas Españolas, vol. 34, n.o 7, pp. 586-591, ago. 2010.

[19] S. M. Alvarado, A. G. Mesinas, y M. Y. Peña, «Psicoprofilaxis Obstétrica: Actualización, definiciones y conceptos», Horizonte Médico (Lima), vol. 14, n.o 4, pp. 53-60, dic. 2014.

[20] R. Mendez y A. Martín, «Factores asociados a la deserción de las Sesiones Educativas de Psicoprofilaxis Obstétrica en primigestas atendidas en el Instituto Nacional Materno Perinatal, Año 2014», Repositorio de Tesis - UNMSM, 2015, Accedido: mar. 20, 2020. [En línea]. Disponible en: http://cybertesis.unmsm.edu.pe/handle /cybertesis/4013.

[21] Á. Sánchez Caraballo, Metodología de la investigación en ciencias de la salud. 2015.

[22] M. A. Batista Zaldívar y J. N. Pérez Guerrero, «Modelo y metodología para la gestión de la ciencia y la innovación en las universidades», Revista Cubana de Educación Superior, vol. 35, n.o 2, pp. 154-168, ago. 2016.

[23] P.-J. Chen, L. Yang, C.-C. Chou, C.-C. Li, Y.-C. Chang, y J.-J. Liaw, «Effects of prenatal yoga on women's stress and immune function across pregnancy: A randomized controlled trial», Complement Ther Med, vol. 31, pp. 109-117, abr. 2017, doi: 10.1016/j.ctim.2017.03.003. 